\title{
THE MODERATING EFFECTS OF PERCEIVED USE AND PERCEIVED RISK IN ONLINE SHOPPING
}

\author{
*Ebru GOZUKARA \\ *Yagmur OZYER \\ **Ipek KOCOGLU \\ *Istanbul Arel University \\ **Gebze Teknik University
}

\begin{abstract}
The purpose of this study is to empirically test the simultaneous effect of both hedonic and utilitarian motivation on search and purchase intentions along with the roles of the perceived ease of use and perceived risk as moderators. The analysis of the data $(N=352)$ through structural equations modeling $(S E M)$ in AMOS reveals that; $i$-) utilitarian and hedonic motivations have positive impact on purchase intention, $i i-)$ although hedonic motivation has a positive influence on search intention, utilitarian motivation is not found to have any positive associations with search intention, iii-) perceived ease of use moderates the relationship between hedonic motivation and search intention but does not have any moderation role in the link between utilitarian motivation and search intention, and iv-) perceived risk has only a moderator role in the relationship between hedonic motivation and purchase intention. Finally, the theoretical and managerial implications of the study are discussed.
\end{abstract}

Keywords: Online shopping, utilitarian motivation, hedonic motivation, perceived ease of use, perceived risk .

\section{INTRODUCTION}

The willingness to purchase or explore products/offerings online, which depends on the shopping motivations of consumers (Bosnjak et al., 2007), is increasingly attracting the attention of researchers and practitioners in the e-commerce literature (Hausman and Siekpe, 2008). Whereas academic research attempts to assess the reason behind consumers' shopping motivations, involving hedonic (i.e. enjoyment, experience, and emotions within the shopping process), and utilitarian (i.e. mission/task-oriented, rational and benefit-based outcome within the shopping process) motivations (Hirschman and Holbrook, 1982), which are found to be important determinants of purchase intention in the marketing literature, few studies focus on both utilitarian and hedonic shopping motivations as simultaneous determinants of purchase and search intentions in the online context (To et al., 2007). This simultaneity gains importance in an emerging market condition, such as Turkey, where online shopping is recently being popular as the economic prosperity of well-educated but time starved consumers increase (Rohm and Swaminathan, 2004). For instance, Turkish consumers increasingly evolve more complex expectations regarding higher quality and higher taste offerings due to the increasing income, education and the person's modernity/living standards reflecting their openness to change and adapt to online shopping. Hence, we argue that Turkey constitutes a suitable case for the empirical examination of the consumers' tendency and the factors moderating both utilitarian and hedonic motivations ' relationship with the search and purchase intentions. Also, while studies examining online purchase intention are ample in online shopping literature (Bosnjak et al., 2007; Hausman and Siekpe, 2008; Kim et al., 2008; Voss et al., 2003), the investigation of consumers' search intention, which has an important role in generating planned or impulsive purchasing, is an underestimated research area in the online context (To et al., 2007). Indeed, purchasing behavior is often measured by the purchase intention as a surrogate (Vijayasarathy, 2004), since consumer's behavioral intention to perform a behavior which is the immediate determinant of actual behavior (Kim et al., 2008). Particularly we discuss that search intention has a powerful impact in promoting purchase through emotional stimulation or the encountering of the shopping information required.

Further, although "the perceived ease of use" factor of internet, such as the availability and accessibility of information resources, the meeting of specific consumer needs, the facilitation to complete the goal task, 
delivering the desired information in less time and accurately (Hausman and Siekpe, 2008), have considerable importance on intention throughout the search process, the moderator role of the perceived ease of use in the relationship between online shopping motivations (e.g. hedonic and utilitarian) and search intention, in the means of improving the online shopping experience is not well understood and emphasized (Garrity et al., 2007). Moreover, the literature highlights that "perceived risk" of internet constitutes an antecedent that directly and negatively affects customers' willingness to shop online and purchase intention (Chang and Tseng, 2011). In this respect, reducing consumers' perceived risks becomes an important factor in enhancing the purchase intention of consumers (Chang and Tseng, 2011). However, although past studies treat perceived risk as an antecedent of purchase intention (Rao et al., 2007; Lian and Lin, 2008; Kim et al., 2008), having a negative effect, there is limited evidence regarding the moderating role of perceived risk in the relationship between hedonic and utilitarian motivations, and purchase intention as well as in the relationship between search intention and purchase intention.

Therefore, the aim of this study is to investigate the impact of hedonic and utilitarian shopping motivations on the online search and purchase intentions, and empirically test the moderator roles of "the perceived ease of use" and "perceived risk" on the relationship between shopping motivations and online search and purchase intentions and on the relationships among shopping motivations and purchase intention as well as search and purchase intentions respectively.

\section{BACKGROUND}

Consumers' motivation to make online shopping can be best explained by the motivation theory, which is constructed on the cognitive and affective motives (Beldona et al., 2005) and which places customer value at the very core of predicting purchase behavior (Chang and Tseng, 2011). Parallel, there exists a general agreement in the literature that consumers evaluate the benefits and risks of online shopping before acting to purchase through utilitarian and hedonic motivations (Soopramanien and Robertson, 2007). According to Holbrook and Hirschman (1982) utilitarian shopping motivation is based on the traditional information processing buying model where the consumer is rationally aiming to maximize utility/efficiency by emphasizing the tangible benefits such as convenience, variety-seeking, quality of merchandise, cost benefit and time effectiveness (Sarkar, 2011; Close and Kukar-Kinney, 2010). According to utilitarian motivation consumers approach online purchase as a cognitive problem-solving activity in which a series of steps should be taken to achieve the desired outcome (Bosnjak et al., 2007). On the other hand, hedonic shopping motivation indicates the emotional arousal involving sensory attributes built on the experiential benefits and sacrifices such as happiness, fantasy, escapism, awakening, sensuality and enjoyment (Overby and Lee, 2006; To et al., 2007). Also, there is a growing evidence in the literature that the utilitarian motivation, which solely encompasses the instrumental benefit associated with the completion of the purchasing act, should be supported with experiential hedonic motivation covering social and emotional worth within the online shopping process (To et al., 2007).

The literature also indicates that the uncertainty associated with the online shopping medium needs to be reduced, where the processed information as an end-product of search intention helps consumers to make the purchasing decision (Huang, 2000). In this context, particularly the acceptance of internet related technologies within the web environment is examined through their "perceived ease of use" in a potential purchase or visit to the website (Hassanein and Head, 2007). Perceived ease of use in the context of online shopping is defined as the extent to which a consumer believes the online channel enables him/her to perform the necessary transaction effectively, providing a performance increase within the process (Davis, 1989; Vijayasarathy, 2004). The perceived ease of use is categorized as an extrinsic motivation to perform an activity because it is perceived to produce valued outcomes that are distinct from the activity itself (Garrity et al., 2007). In addition to the perceived ease of use regarding the online channel, "perceived risk" in the context of online shopping is the critical predictor of attitude towards online shopping and purchase intention (Lee and Turban, 2001). Perceived risk is defined as "a consumer's belief about the potential uncertain and negative outcomes from the online transaction" (Kim et al., 2008). Despite the fact that most of the purchasing decisions involve risks, decisions associated with online shopping tend to have higher perceived risk which decreases the likelihood of risk-averse consumers to shop online (Li and Huang, 2010). According to the previous studies in the online shopping context, perceived risk is categorized under three predominant 
types namely; financial risk, product risk, and information risk. Financial risk, related with the marketing channel rather than the product/service offered, involves the opportunity cost and time; product risk includes problems associated with the product or service itself; and information risk is related with the security and the privacy of the online transaction (Kim et al., 2008).

Having established the characteristics of online shopping motivations, the perceived ease of use and perceived risk of online channels, we develop arguments regarding how online shopping motivations impact online search and purchase intentions, and the moderator role of the perceived ease of use and perceived risk of online channels between shopping motivations, and search and purchase intentions.

\section{HYPOTHESIS DEVELOPMENT}

In this section, the experimental constructs are explained in detail and research hypotheses are developed. Figure 1 depicts an overview of the hypotheses and highlights the conceptual model developed in this research. The model presented incorporates two essential factors as antecedents of search and purchase intention in online shopping context; (1) utilitarian motivation, and (2) hedonic motivation. Additionally two moderators are included in the model; perceived ease of use and perceived risk, respectively moderating; (1) the relationship between the two shopping motivations (i.e. utilitarian and hedonic) and search intention and (2) the relationship between the two shopping motivations and purchase intention, and (3) the relationship between search intention and purchase intention.

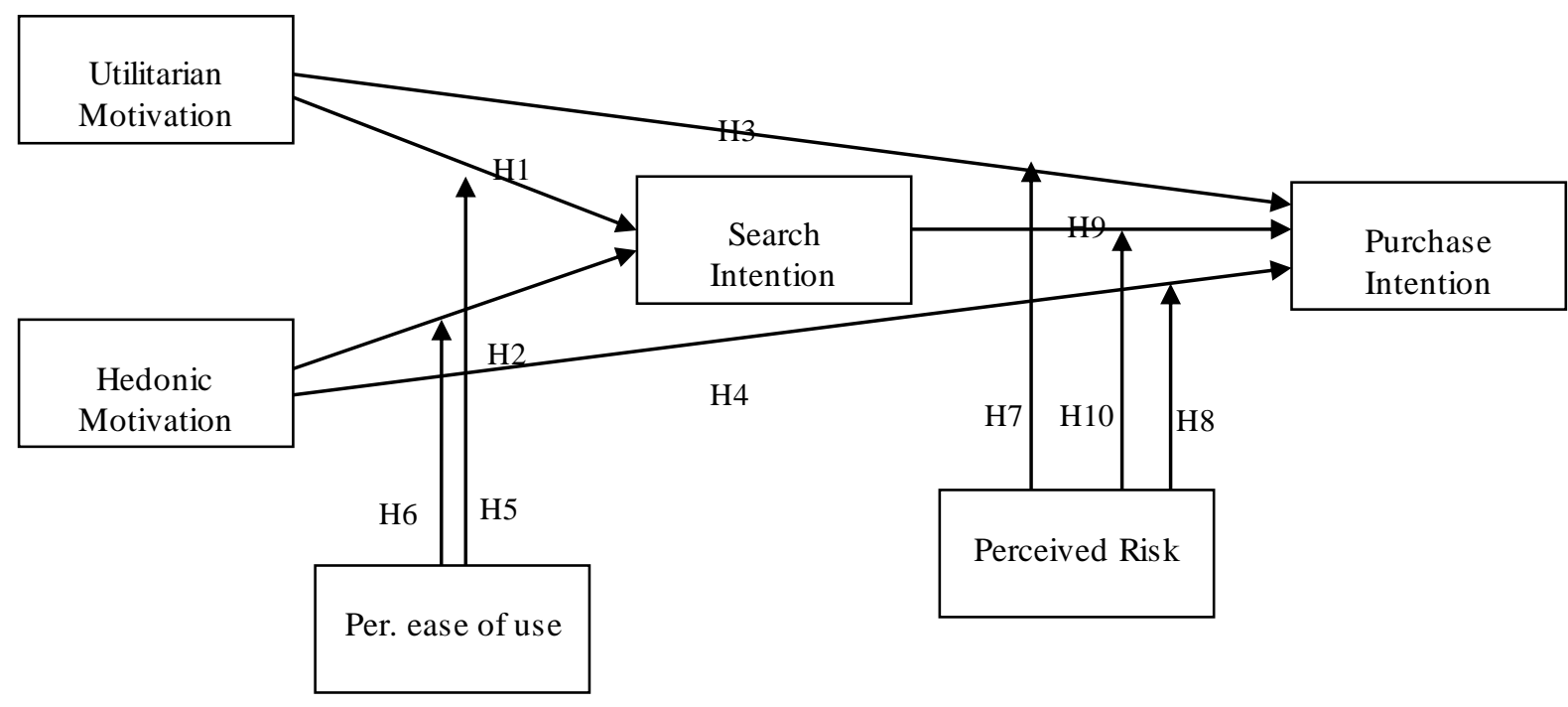

Figure 1. The proposed conceptual model

\section{The relationships between shopping motivations and online search/purchase intention}

We argue that utilitarian shopping motivation impacts the online search intention through creating a learning orientation (Overby and Lee, 2006). This is such that, utilitarian shopping motivation enforces consumers to learn more, make better assessments and judgments on products or services offered online (To et al., 2007). For instance, writers indicate that individuals with higher assessment of functional benefits are mo re inclined towards making cognitive effort in order to search, explore and utilize new information regarding the online offers (Li and Huang, 2010). In this way, utilitarian shopping motivation of people influences their online search intention via browsing a variety of data and sources (Bridges and Florsheim, 2008; Vijayasarathy, 2004). Indeed, since internet has overcame the limitation of space and time, consumers can reach their target with less time and effort (To et al., 2007). Here, people have more alternatives to learn and chose through the 
opportunities provided by online medium, promoting the likelihood of being involved in a deeper search process (Read et al., 2011). Therefore, we hypothesize that;

H1: Utilitarian shopping motivation is positively related to the online search intention.

Hedonic shopping motivation also enhances online search intention by providing emotional and sensual motivations (To et al., 2007). For instance, To et al. (2007) mention that pleasure of exploration within online shopping which enables consumers to learn about new trends, understand the information about brands, products and services is an important element of hedonic motivation which encourages consumers to search prior to act. Here, sensual stimulation and freedom to search are the main factors encouraging consumers to gather information on products and services they are willing to purchase. Also, hedonic shopping motivation impacts online search intention through constituting a medium of dynamic interaction between product and the consumer where consumers gain authority and status (i.e. having all the control of the shopping process, deciding what products to see, when to place an order and when to receive delivery) (O'Brien, 2010). Here, consumers get engaged in a sensually satisfying process by aesthetics, novelty, and playfulness (Overby and Lee, 2006). Therefore we hypothesize that;

H2: Hedonic shopping motivation is positively related to the online search intention.

Besides the online search intention, we put forward that consumers' utilitarian shopping motivation also influences the online purchase intention by providing "time" awareness. According to the economics of information approach the perceived efficiency of buying online is dependent on the time costs where time needed to find and buy the best product for the lowest price determines which shopping channel consumers will choose. Indeed, consumers seek to expand their flexibility in decision making in order to optimize their choices regarding the price and quality of products. In addition, utilitarian shopping motivation impacts the online purchase intention by highlighting the concern of "convenience" in online shopping context (To et al., 2007). As online shopping enables consumers to get access to their needs regardless of time and space, and provides a more comfortable and convenient non-stop shopping environment (Soopramanien and Robertson, 2007), consumers purposefully chose online channel for shopping. Hence we hypothesize that;

H3: Utilitarian shopping motivation is positively related to online purchase intention.

Hedonic shopping motivation also enhances online purchase intention through the feelings of escapism, diversion, aesthetics, enjoyment, and emotional release provided by the ability of a website to enhance experience and entertain (Overby and Lee, 2006). For instance, online shopping experience is enriched through navigational aids, web atmosphere, novelty, colors, movement, music and vividness (Bosnjak et al., 2007). Here, the more emphasis the consumer puts on excitement, novelty, sensual arousal, enjoyment and experience, the more likely that the consumer will choose purchasing via online shopping. Also, the anonymity of online shopping allows consumers to enjoy shopping without any negative influence by the external environment (Chug and Chang, 2005). Therefore;

H4: Hedonic shopping motivation is positively related to online purchase intention.

\section{The moderating effect of the perceived ease of use in the relationship between shopping motivations and search intentions}

We argue that the relationship between utilitarian shopping motivation and search intention is influenced by the efficiency of online shopping environment (e.g., the perceived ease of use) (Park and Gretzel, 2010). For instance, the less complexity, and more functionality, information content, navigation, and the controllability of the information systems, the higher functional benefits are perceived resulting in increased deliberation for considering the price, information and features regarding the product/service - search intention (Hausman and Siekpe, 2008; Overby and Lee, 2006). Hoffman and Novak (1996) also note that perceived ease of use of online shopping context leads consumers to enter in a state of flow which is established by high levels of skills and control, high levels of challenge and arousal, focused attention and interactivity. Also the perceived ease of use of online medium leverages the utilitarian shopping motivation and search intention by saving time and effort (To et al., 2007), as perceived time scarcity is an important factor which highlights the importance of perceived usefulness within the online channel in shopping (Koiso-Kantilla, 2005). Therefore; 
H5: The perceived ease of use of online medium positively moderates the relationship between utilitarian shopping motivation and online search intention.

High levels of the perceived ease of use of online medium also strengthens the influence of hedonic shopping motivation on the online search intention, as it promotes the joy of exploration through facilitating the access to relevant information as well as the motivation for exploration (Bridges and Florsheim, 2008). In fact, a useful online channel establishes a platform through which technical features and prices of products and services can be easily compared that increases the impact of hedonic motivations perceived on search intention online (Lee and Lin, 2005). Also the perceived ease of use in online shopping enhances the impact of hedonic motivation on search intention by offering consumers the excitement of having more choices, more readily available information, transparent prices and lower transaction costs (Rao et al., 2007). Hence;

H6: The perceived ease of use of online medium positively moderates the relationship between hedonic shopping motivation and online search intention.

\section{The moderating role of perceived risk in the relationship between shopping motivations and purchase intention}

We put forward that perceived risk has a negative role in the relationship between utilitarian motivation and purchase intention through diminishing consumers' trust of online service providers which culminates a loss of consumer's perception on the online retailer's service quality, reliability and credibility (Lian and Lin, 2008). For instance, perceived risk negatively influences the purchase intention by increasing the fear of information disclosure which creates the awareness of danger regarding the likelihood of the personal data's unauthorized use (Kim et al., 2008; Lian and Lin, 2008). Also, the perceived risk of the online shopping environments induces load and executive stress to people due to the difficulty of dealing with excessive information and lower decision accuracy which results in the tendency to avoid exposure (Huang, 2000). To et al. (2007), for instance, mention that as perceived risk increases the benefits associated with information availability and the facilitator nature of internet for consumers to acquire, save and copy information efficiently are replaced by the fear of being lost in this sea of information, the reluctance to be exposed to a greater complexity and variety of information where the information to be processed gradually increases. Therefore;

H7: Perceived risk of online medium negatively moderates the relationship between utilitarian shopping motivation and online purchase intention.

Perceived risk of online medium also reduces the impact of hedonic motivations on the online purchase intention by inducing a sense of uncontrollable and uncertain future within the online transactions (Kim et al., 2008). For instance, Son and Han (2011) indicate that the controllability is a very important criteria for the establishment of a psychological connection, and that it tends to pose less inclination to worry about possible negative outcomes. Here, the subjective uncertainty of the outcomes and numerous inherent losses such as; injustices of pricing, violations of privacy, transmission of inaccurate information, unauthorized tracks of transactions and unauthorized uses of credit cards diminish the emotion-laden bond to online shopping medium (Read et al., 2011). In fact, consumers acknowledge the fact that online service providers assemble their names, e-mail addresses, phone numbers, and home addresses as well as shopping preferences, under the process of data collection which is a very important step for online channels to offer customized online services and product to consumers (Kim et al., 2008). Hence;

H8: Perceived risk of online medium negatively moderates the relationship between hedonic shopping motivation and online purchase intention.

\section{The relationship between online search intention on purchase intention}

Past researches indicate that consumers' increased search intentions has an important role in enhancing purchase intention by enriching the information base of shoppers through the use of explorative mass communication. Here, search intention enhances purchase intention by meeting consumers' specific need of accessing informational content previous to the purchasing act, allowing users to get desired and systematically organized information in less time, with less effort (Soopramanien and Robertson, 2007). The information processing view of consumer behavior suggest that pre-purchase search attempts lead to a 
purchasing act both through the explorative shopping motivation and by the goal-oriented shopping (To et al., 2007). Also, the availability and speed of informational content through online mediums such as internet give consumers the freedom and power to gain flexibility in making choices and increase the status and authority for future purchase intention, intrinsically strengthening decision quality and supporting the sense of "making the appropriate decision" (Hausman and Siekpe 2008). Search intention also increases the perception of accuracy and completeness regarding online information gathered indirectly. As the time spent and information seeking activities increase the depth of interaction bet ween the online service provider and the consumer is better able to fulfill the sense of a good purchasing decision which provides what is needed to conduct the transaction in a controlled manner (Kim et al., 2008). Therefore;

H9: Online search intention is positively related to online purchase intention.

\section{The Moderating effect of perceived risk in the relationship between online search and purchase intentions}

In this study, we argue that perceived risk of the online shopping medium moderates the impact of search intention on the purchase intention through; i-) increasing the uncertainties associated during the shopping process, ii-) decreasing the assessment of service quality, iii-) decreasing consumers' ability to control the actions of the online vendor, and iv-) blocking user interactivity and leading to a diminishing interest (Bridges and Florsheim, 2008; Hoffman et al., 1999). Specifically, since perceived risk depends on consumers' subjective uncertainty of the outcomes and unfavorable consequences, the degree of satisfaction on the actual purchasing experience relies on the sense of risk. When consumers perceive risk while evaluating the products or services (i.e. the decision making process), the uncertainties encountered about the online medium may prevent them to foresee actions in advance and create reluctance to terminate the online transaction initiated by the search process with an actual purchase (Kim et al., 2008). In addition, as Rao et al. (2007) mention that although the pre-purchase searching activity is a transparent process by its nature which requires the parties to rely on each other's goodwill and effort to mutually benefit from the transaction, perceived risk constraints the consumers' freedom of movement in track of their buying goals and expected outcomes. Therefore we hypothesize that;

H10: Perceived risk negatively moderates the relationship between search intention and purchase intention.

\section{RESEARCH DESIGN Measures and sampling}

To test the above hypotheses, multi-item scales adopted or developed from prior studies for the measurement of the constructs were used. All constructs were measured using 5-point Likert scales ranging from 'strongly disagree' (1) to 'strongly agree' (5). Appendix contains the questionnaire.

We used the parallel translation method in developing the Turkish language questionnaire. It was first translated into Turkish by one person and then translated back into English by a second person to enhance translation equivalence. Some changes were made in the wording to clarify the semantics in the Turkish version. The suitability of the Turkish version of the questionnaires was then pre-tested by 40 consumers who have similar demographics with the target population of this study.

Respondents of this study are adults in Turkey who have Internet shopping experience. An Internet survey was not considered as the respondents of such a survey would often be young students and heavy Internet users, which might cause bias in the sample (Zhang, 2000). This study adopted three different sources of sample populations to minimize the bias of the sample as suggested by To et al. (2007). Sources of samples for this study are: people in the industry, street distribution, and convenient sampling. For the first group, we selected 15 companies and distributed 20 questionnaires each to be filled out by the employees or their relatives who had Internet shopping experience. A total of 300 questionnaires were distributed to people in the industry, 145 were received, and among them 123 valid responses were received. The valid response rate was $35.14 \%$. The reason behind selecting different companies is to ensure the diversity of sample source and the reason behind selecting ten questionnaires from each company is trying to minimize the impact of any single company or individual. As part of the street distribution sampling, we distributed 200 questionnaires in 
Istanbul. Among the 200 questionnaires distributed in total, 135 responses were received, of which 102 were valid. The valid response rate was $51 \%$. Finally with regard to convenient sampling, the study distributed 250 questionnaires to the students of EMBA and graduate programs of three universities in Istanbul. Among the 250 questionnaires distributed, 130 were received back of which 127 were valid. The valid response rate was $50.8 \%$. In summary, the total number of questionnaires distributed was 750 , of which 352 were valid after eliminating incomplete and faulted questionnaires. The valid response rate was $46.80 \%$.

The subjects were required to answer the items of the questionnaire based on their impressions of their most frequently shopped website. They were then instructed to indicate the degree of which each statement is a representation of their thoughts and feelings and the way they interact online.

The number of male and female respondents in this study was quite close, where the percentage of male respondents $(55 \%)$ is slightly more than that of female respondents. People having ages between 25 and 34 comprise about $52.0 \%$ of the respondents. As for the educational background, most of the respondents were college graduates $(75.6 \%)$. Internet usage history of most respondents was "more than 4 years" $(81.5 \%)$, followed by "2-4 years". More than $50 \%$ of the respondents used Internet more than 18 hours a week.

\section{ANALYSIS AND RESULTS}

\section{Validity and reliability}

We evaluated the reliability and validity of our constructs using confirmatory factor analysis (CFA) (Anderson and Gerbing, 1988; Fornell and Larcker, 1981). By using AMOS 4.0, we investigated all six constructs (involving 36 question items) in one CFA model shown in Table 1. One item from the hedonic motivation and, search intention scales tended to crossload on other factors. An examination of these items revealed that deleting them would not deteriorate the content validity of the hedonic motivation and search intention. 
Journal Of Global Strategic Management | V. 8 | N. 2 | 2014-December | isma.info | 71-85 | DOI:10.20460/JGSM.2014815643

Table 1. The Results of Confirmatory Factor Analysis

\begin{tabular}{|c|c|c|c|c|c|c|}
\hline Items & $\begin{array}{l}\text { Utilitarian } \\
\text { Motivation }\end{array}$ & $\begin{array}{l}\text { Hedonic } \\
\text { Motivation }\end{array}$ & $\begin{array}{l}\text { Perceived } \\
\text { Ease of use }\end{array}$ & $\begin{array}{l}\text { Perceived } \\
\text { Risk }\end{array}$ & $\begin{array}{l}\text { Search } \\
\text { Intention }\end{array}$ & $\begin{array}{l}\text { Purchase } \\
\text { Intention }\end{array}$ \\
\hline $\begin{array}{l}\text { The products and/or services I purchased from the Internet } \\
\text { retailer were a good buy. }\end{array}$ & 0,85 & & & & & \\
\hline This Internet retailer offers a good economic value. & 0,83 & & & & & \\
\hline $\begin{array}{l}\text { The price of the products and/or services I purchased from } \\
\text { the Internet retailer is at the right level and given the quality. }\end{array}$ & 0,74 & & & & & \\
\hline I can achieve what I want through this internet retailer. & 0,69 & & & & & \\
\hline When making a purchase from this Internet site I feel relaxed. & & 0,89 & & & & \\
\hline $\begin{array}{l}\text { This Internet retailer doesn't just sell product or services —it } \\
\text { entertains me. }\end{array}$ & & 0,69 & & & & \\
\hline $\begin{array}{l}\text { Making a purchase from this Internet retail site "gets me } \\
\text { away from it all". }\end{array}$ & & 0,59 & & & & \\
\hline The process of transaction on the Web is convenient. & & & 0,80 & & & \\
\hline Online shopping would be easy to use. & & & 0,78 & & & \\
\hline Interfaces of Web stores are user friendly. & & & 0,78 & & & \\
\hline $\begin{array}{l}\text { We can trust the brand and reputation of the stores on the } \\
\text { Web. }\end{array}$ & & & 0,74 & & & \\
\hline Waiting time on the Web stores is short. & & & 0,76 & & & \\
\hline There are many useful tools for shopping on the Web stores. & & & 0,73 & & & \\
\hline Online shopping would be clear and understandable. & & & 0,71 & & & \\
\hline $\begin{array}{l}\text { I can quickly find the Web stores I want when I go on the } \\
\text { Internet. }\end{array}$ & & & 0,68 & & & \\
\hline $\begin{array}{l}\text { It is easy to search for the product information when } \\
\text { shopping on the Web. }\end{array}$ & & & 0,68 & & & \\
\hline $\begin{array}{l}\text { I can easily find the product I want when shopping on the } \\
\text { Web. }\end{array}$ & & & 0,65 & & & \\
\hline $\begin{array}{l}\text { How would you rate your overall perception of risk from this } \\
\text { site? }\end{array}$ & & & & 0,87 & & \\
\hline I can't trust this online shopping company. & & & & 0,77 & & \\
\hline $\begin{array}{l}\text { I am concerned that I may not get the product when } \\
\text { purchasing from this Website. }\end{array}$ & & & & 0,76 & & \\
\hline $\begin{array}{l}\text { Purchasing from this Website would involve more product } \\
\text { risk (i.e. not working, defective product) when compared with } \\
\text { more traditional ways of shopping. }\end{array}$ & & & & 0,72 & & \\
\hline $\begin{array}{l}\text { Purchasing from this Website would involve more financial } \\
\text { risk (i.e. fraud, hard to return) when compared with more } \\
\text { traditional ways of shopping. }\end{array}$ & & & & 0,72 & & \\
\hline $\begin{array}{l}\text { I am concerned that I might be overcharged when purchasing } \\
\text { from this Website. }\end{array}$ & & & & 0,67 & & \\
\hline $\begin{array}{l}\text { I am concerned that my personal information may not be kept } \\
\text { when purchasing from this Website. }\end{array}$ & & & & 0,59 & & \\
\hline I regularly read/watch advertisements to compare websites. & & & & & 0,87 & \\
\hline $\begin{array}{l}\text { I decide on visiting competing websites for shopping on the } \\
\text { basis of advertisements. }\end{array}$ & & & & & 0,84 & \\
\hline $\begin{array}{l}\text { I often talk to my friends about their experience regarding } \\
\text { competing websites. }\end{array}$ & & & & & 0,76 & \\
\hline $\begin{array}{l}\text { I explored many competing websites in order to find an } \\
\text { alternative to this site. }\end{array}$ & & & & & 0,64 & \\
\hline I purchase products or services online. & & & & & & 0,89 \\
\hline I will continue shopping online in the future. & & & & & & 0,86 \\
\hline Shopping online is a wonderful way to shop online. & & & & & & 0,79 \\
\hline I am likely to purchase the products(s) on this site. & & & & & & 0,78 \\
\hline I am likely to recommend this site to my friends. & & & & & & 0,73 \\
\hline $\begin{array}{l}\text { I am likely to make another purchase from this site if I need } \\
\text { the products that I will buy. }\end{array}$ & & & & & & 0,60 \\
\hline
\end{tabular}


The resulting measurement model was found to fit the data reasonably well: $\chi^{2}{ }_{(474)}=1085.48$, comparative fit index $(\mathrm{CFI})=.92$, incremental fit index $(\mathrm{IFI})=.92$, Tucker-Lewis Index $(\mathrm{TLI})=.91, \chi^{2} / \mathrm{df}=2.28$, and rootmean-square error of approximation $(\mathrm{RMSEA})=.061$. Also, the parsimonious normed fit index $(\mathrm{PNFI})=$ .78 , which is above the cut-off point of .70. In addition, all items loaded significantly on their respective constructs (with the lowest $t$-value being 9.97), providing support for convergent validity.

To assess the discriminant validity, a series of two-factor models, recommended by Bagozzi et al. (1991) were estimated in which individual factor correlations, one at a time, were restricted to unity by using AMOS 4.0. The fit of the restricted models was compared with that of the original model. In total, we performed 15 models - 15 pairs of comparisons - using AMOS 4.0. The chi-square change $\left(\chi^{2}\right)$ in each model, constrained and unconstrained, were significant, $\Delta \chi^{2}>3.84$, which suggests that constructs demonstrate discriminant validity.

Table 2 reports the reliabilities of the multiple-item, reflective measures, along with construct correlations and descriptive statistics for the scales. Table 1 also demonstrates that all reliability estimates - including coefficient alphas, average variance extracted for each construct, and AMOS 4.0 based composite reliabilities - are well beyond or close to the threshold levels suggested by Nunnally (1978) and Fornell and Larcker (1981). As a check for discriminant validity, the variance extracted for each construct was greater than the squared latent factor correlations between pairs of constructs in Table 2. After conducting these tests, we conclude that our measures have adequate discriminant and convergent validity.

Table 2. Correlations and descriptive statistics

\begin{tabular}{|c|c|c|c|c|c|c|c|c|c|}
\hline Mean & S.D. & & Variables & 1 & 2 & 3 & 4 & 5 & 6 \\
\hline 2.55 & 0.87 & 1 & Hedonic & - & & & & & \\
\hline 3.67 & 0.72 & 2 & Utilitarian & $0.39^{* *}$ & - & & & & \\
\hline 3.08 & 0.80 & 3 & Perceived Risk & $-0.35^{* *}$ & $-0.52^{* *}$ & - & & & \\
\hline 3.77 & 0.67 & 4 & Perceived ease of use & $0.34^{* *}$ & $0.65^{* *}$ & $-0.50^{* *}$ & - & & \\
\hline 2.87 & 0.94 & 5 & Search Intention & $0.41^{* *}$ & $0.28^{* *}$ & $-0.29^{* *}$ & $0.33^{* *}$ & - & \\
\hline \multirow[t]{4}{*}{3.60} & 0.84 & 6 & Purchase Intention & $0.44^{* *}$ & $0.64^{* *}$ & $-0.57^{* *}$ & $0.64^{* *}$ & $0.39^{* *}$ & - \\
\hline & & & Composite reliability & 0.77 & 0.86 & 0.89 & 0.92 & 0.88 & 0.91 \\
\hline & & & Variance extracted & 0.55 & 0.61 & 0.55 & 0.56 & 0.64 & 0.62 \\
\hline & & & Cronbach's a & 0.76 & 0.86 & 0.91 & 0.92 & 0.87 & 0.91 \\
\hline
\end{tabular}

$* \mathrm{p}<0.05, * * \mathrm{p}<0.01$

\section{Hypotheses testing}

To test our hypotheses, we performed a structural equation modeling analysis. Table 3 demonstrates the relationships among utilitarian motivation, hedonic motivation, search intention and purchase intention. As can be seen from Table 3, the utilitarian motivation is not related to search intention $(\beta=.055, p>.01)$, not supporting $\mathrm{H} 1$, and is positively related to purchase intention $(\beta=.635, p<.01)$, supporting $\mathrm{H} 3$. The results also indicate that the hedonic motivation is positively related to search intention $(\beta=.553, p<.01)$ and purchase intention $(\beta=.118, p<.10)$, supporting $\mathrm{H} 2$ and $\mathrm{H} 4$. Finally, the search intention affects the purchase intention $(\beta=.135, p<.05)$, supporting $\mathrm{H} 9$. 
Table 3. Path Model

\begin{tabular}{llll}
\hline Hypothesis & Path & Path Value & Result \\
\hline Hypothesis 1 & Utilitarian motivation $\rightarrow$ Search intention & 0.055 & Not Supported \\
Hypothesis 2 & Hedonic motivation $\rightarrow$ Search intention & $0.553^{* * *}$ & Supported \\
Hypothesis 3 & Utilitarian motivation $\rightarrow$ Purchase intention & $0.635^{* * *}$ & Supported \\
Hypothesis 4 & Hedonic motivation $\rightarrow$ Purchase intention & $0.118^{*}$ & Supported \\
Hypothesis 9 & Search motivation $\rightarrow$ Purchase intention & $0.135^{* *}$ & Supported \\
\hline Fit Indices: GFI= $0.92, \mathrm{CFI}=0.96, \mathrm{IFI}=0.96, \mathrm{TLI}=0.94, \mathrm{RMSEA}=0.064, \chi_{(110)}^{2}=267.25, \chi^{2} / \mathrm{df}=2.43$ \\
\hline $\mathrm{p}<0.10, * * \mathrm{p}<0.05, * * * \mathrm{p}<0.01$
\end{tabular}

To test the hypotheses regarding the moderator role of perceived ease of use and perceived risk, consistent with the literature, a moderated multiple hierarchical regression analysis was used (Irwin and McClelland, 2001). Because of the possibility of multicollinearity, perceived ease of use, hedonic motivation, utilitarian motivation, search intention and perceived risk measures were mean-centered before performing the analysis as suggested by (Cohen and Cohen, 1983). We estimated variance inflation factors (VIF) to examine multicollinearity levels and found the results (VIFs < 10) to be below a harmful level (Neter et al., 1990). Following the suggestion of Cohen and Cohen (1983), we also compared the $\mathrm{R}^{2}$ regression equation without the cross-product with the $\mathrm{R}^{2}$ of the regression equation with the cross-product to determine if the incremental $R^{2}\left(\Delta R^{2}\right)$ due to the interaction is significant. Results show that the inclusion of the interaction terms on the hierarchical regression added a significant variance explanation $(p<.05)$ in our search intention and purchase intention model. As shown in Table 4, the coefficient of the interaction term demonstrates that, with a high level of perceived ease of use, hedonic motivation has a positive association with search intention $(\beta=.133, p<.05)$, supporting H6. However, perceived ease of use does not moderate the relationship between utilitarian motivation and search intention $(\beta=-.083, \mathrm{p}>.1)$, not supporting H5.

\section{Table 4. Moderating effect of perceived ease of use on search intention}

\begin{tabular}{lcc}
\hline & \multicolumn{2}{c}{ Search Intention } \\
\cline { 2 - 3 } & Model 1 & Model 2 \\
\hline Main effects & 0.008 & -0.007 \\
$\quad$ Utilitarian motivation & $0.338^{* *}$ & $0.329^{* *}$ \\
Hedonic motivation & $0.21^{* *}$ & $0.237^{* *}$ \\
Perceived ease of use & & \\
& & \\
Interactions & & -0.083 \\
Perceived ease of use x Utilitarian motivation & & $0.133^{*}$ \\
Perceived ease of use x Hedonic motivation & & \\
& & 0.222 \\
$\mathrm{R}^{2}$ & 0.172 & 0.05 \\
$\Delta \mathrm{R}^{2}$ & & 19.73 \\
$\mathrm{~F}$ & 72.51 & \\
\hline
\end{tabular}

Note: Regression coefficients are standardized.

$* \mathrm{p}<0.05, * * \mathrm{p}<0.01$

Table 5 shows the moderating effect of perceived risk on purchase intention. Results show that hedonic motivation has a negative effect on purchase intention $(\beta=-.202, p<.01)$, when perceived risk is higher, 
supporting H8. However, perceived risk does not moderate the relationship between utilitarian motivation and purchase intention $(\beta=-.019, p>.1)$, as well as the relationship between search and purchase intention $(\beta=.011, p>.1)$, respectively not supporting $\mathrm{H} 7$ and $\mathrm{H} 10$.

Table 5. Moderating effect of perceived risk on purchase intention.

\begin{tabular}{|c|c|c|}
\hline & \multicolumn{2}{|c|}{ Purchase Intention } \\
\hline & Model 1 & Model 2 \\
\hline \multicolumn{3}{|l|}{ Main effects } \\
\hline Utilitarian motivation & $0.435 * *$ & $0.434 * *$ \\
\hline Hedonic motivation & $0.118 * *$ & $0.1 *$ \\
\hline Search & $0.154 * *$ & $0.17 * *$ \\
\hline Perceived risk & $-0.251 * *$ & $-0.226 * *$ \\
\hline \multicolumn{3}{|l|}{ Interactions } \\
\hline Perceived risk $\mathrm{x}$ Utilitarian motivation & & 0.019 \\
\hline Perceived risk $\mathrm{x}$ Hedonic motivation & & $-0.202 * *$ \\
\hline Perceived risk x Search intention & & 0.011 \\
\hline$\overline{R^{2}}$ & 0.52 & 0.56 \\
\hline$\Delta R^{2}$ & & 0.04 \\
\hline $\mathrm{F}$ & 96.4 & 62.92 \\
\hline
\end{tabular}

Note: Regression coefficients are standardized.

$* \mathrm{p}<0.05, * * \mathrm{p}<0.01$

\section{DISCUSSION AND IMPLICATIONS}

First, theoretically this study in line with previous findings in the literature (Childers et al., 2001; Overby and Lee, 2006; To et al., 2007) validates that both utilitarian and hedonic motivations of consumers are effective in determining the purchase decision. However, interestingly utilitarian motivation on the contrary to To et al.'s (2007) research, is found to have no significant impact on search intention. It is then evident that the utilitarian motivation mostly driven by convenience and cost and time saving does not lead the modern e consumers to engage in a pre-purchase information search activity. The reason may be the consumers' determination to obtain the expected output namely the product/service offered online. For instance the taskoriented and problem-solving nature of utilitarian motivation directly drags e-consumers to complete the transaction instead of being involved in a so called "time consuming" search activity. Yet, interesting and highly enjoyable shopping experience enhances the browsing of websites which can in turn promote an impulsive purchase intention.

This study also shows that although perceived ease of use strengthens the hedonic motivation's link with the search intention, its presence is not effective in creating a significant link between utilitarian motivation and search intention. This indicates that consumers concentrate mainly on the tangible benefits of the offering they are about to purchase instead of focusing on the experience they have during the online transaction (Sarkar, 2011). This causes a disproportionally weighted importance to the product/service attributes, price, quality and variety. Also, this study demonstrates that perceived risk rather than being a determinant of purchase intention has a relatively varying modifier power on the consumer motivations, explicitly utilitarian and hedonic motivations. The results particularly reveal that purchase intention is not influenced by the presence of perceived risk if the consumer motivation leading to the online purchase is utilitarian. Yet the interruption of the relationship between hedonic motivation and purch ase intention by perceived risk results in diminished purchase intention. On the basis of the results we interpret that the hedonic motivation mainly dominated by entertainment, emotional arousal, enjoyment, adventure and authority/status is predominantly influenced by the perceived negative image resulting from perceived risk as to further damage or even destroy the joy-laden online shopping experience. However the utilitarian motivation is not precluded by perceived risk to stop the e-consumers from purchasing the online offering which has been at first decided to be purchased. 
Finally, this study adds new insights to the e-commerce literature in the context of an emerging market, Turkey. Although the results present that purchase intention is dependent both on utilitarian and hedonic motivations, search intention is found to be dependent only on the hedonic motivation of Turkish econsumers (e.g. different than the study of To et al. (2007) which found a significant relationship between both consumer motivations hedonic and utilitarian with search intention). Also, both perceived ease of use and perceived risk has only a moderating role on hedonic motivation's relationship with the search and purchase intentions. As suggested by Gefen (2000) familiarity breeds comfort towards any purchase or involvement in the online context. Since the Turkish e-consumers are being newly engaged in such online shopping transactions, they are in search of an entertaining experience if they are to make pre-purchase search.

Besides the above contributions, we should also note that there are some methodological limitations of this study. Our research is prone to common method bias since, in the questionnaire, the dependent variable was answered by the same respondents that ans wered the independent variable, in a cross-sectional manner. As with all cross-sectional research, the relationship tested in this study represents a snapshot in time. While it is likely that the conditions under which the data were collected will essentially remain the same, there are no guarantees that this will be the case. In addition, due to the nature of data, the generalizability of sampling is another limitation of this study. The study was conducted in a specific national context, Turkish firms in general and Istanbul district in particular. It is important to note that readers should be cautious when generalizing the results to different cultural contexts. In this regard, a Turkish sample involving Istanbul district, like that of any culturally bound research, be it a major industrialized city in the U.S. Europe or Asia, etc. imposes some constraints on the interpretation and application of the results.

\section{CONCLUSION}

In this study, we investigated the intertwined relationships among consumer motivation s including utilitarian and hedonic, search intention and purchase intention also in the presence of perceived ease of use and perceived risk. The results show that both hedonic and utilitarian motivations positively influence purchase intention but search intention depends solely on hedonic motivation. It is also evident from the results that perceived ease of use has a positive moderator role in the relationship between hedonic and search intention but does not have any moderation effect in the relationship between utilitarian motivation and search intention. Moreover this study demonstrates that perceived risk has a negative moderator role in the relationship between hedonic motivation and purchase intention but does not interact with utilitarian motivation to create a negative influence on purchase intention. However, the presented conceptual model does not capture the alternative moderator or mediator variables in the intertwined relationships between consumer motivations and search and purchase intentions, such as; consumer trust and familiarity with the online environment. Future research may replicate this study by including these factors as moderators and be able to explore a factor triggering utilitarian motivation's link with search intention as well as an intensifier of the relationship between consumer motivations and purchase intention. Thus we believe that future researchers will find the area of consumer motivations and perceptions in online shopping a rich and fruitful area for the literature. 


\section{REFERENCES}

Anderson, J.C., Gerbing, D.W. (1988), Structural equation modeling in practice: a review and recommended two-step approach. Psychological Bulletin, 103, pp. 411-423.

Bagozzi, R.P., Yi, Y., Phillips, L.W. (1991), Assessing construct validity in organizational research, Administrative Science Quarterly, 36, pp.421-459.

Beldona, S., Morrison, A.M., O'Leary, J. (2005), Online shopping motivations and pleasure travel products: a corres pondence analysis, Tourism Management, 26, pp.561-570.

Bosnjak, M., Galesic, M., Tuten, T. (2007), Personality determinants of online shopping:Explaining online purchase intentions using a hierarchical approach, Journal of Business Research, 60, pp.597-605.

Bridges, E., Florsheim, R. (2008), Hedonic and utilitarian shopping goals: The online experience, Journal of Business Research, 61, pp.309-314.

Chang, E-C., Tseng, Y-F. (2011), Research note: E-store image, perceived value and perceived risk, Journal of Business Research, In Press.

Chug, C.C., Chang, S. (2005), Discussion on the behavior intention model of consumer online shopping. Journal of Business Management, 11, pp.41-57.

Childers, T.L., Carr, L.C., Peck, J., Carson, S. (2001), Hedonic and utilitarian motivations for online retail shopping behavior, Journal of Retailing, 77, pp.511-535.

Close, A.G., Kukar-Kinney, M. (2010), Beyond buying: Motivations behing cons umers' online shopping cart use, Journal of Business Research, 63, pp.986-992.

Cohen, J., Cohen, P. (1983), Applied multiple regression/correlation analysis for the behavioral sciences, Erlbaum, New Jersey.

Davis, F.D. (1989), Perceived Usefulness, Perceived Ease of Use, and User Acceptance of Information Technology, MIS Quarterly, 13, pp.319-340.

Fornell, C., Larcker, D.F. (1981), Evaluating structuralequation models with unobservable variables and measurement error, Journal of Marketing Research, 18, pp.39-51.

Forsythe, S., Liu, C., Shannon, D., Gardner, C.L. (2006), Development of a scale to measure perceived benefits and risks of online shopping. Journal of Interactive Marketing, 20, pp.55-75.

Garrity, E.J., O'Donnell, J.B., Kim, Y.J., Sanders, G. (2007), Lawrence. An Extrinsic and Intrinsic Motivation-Based Model for Measuring Consumer Shopping Oriented Web Site Success In Bandyopadhyay, S. (ed) Contemporary Research In E-Branding, 1st Edn. IGI Publishing, London, pp.241-261.

Gefen, D. (2000), E-Commerce: The role of familiarity and trust, Omega: The International Journal of Management Science, 28, pp.725-737.

Hassanein, K., Head, M. (2007), Manipulating perceived social presence through the web interface and its impact on attitude towards online shopping, International Journal Human-Computer Studies, 65, pp.689-708.

Hausman, A.V., Siekpe, J.S. (2008), The effect of web interface features on cons umer online purchase intentions, Journal of Business Research, 62, pp.5-13.

Hirschman, E.C., Holbrook, M.B. (1982), Hedonic Consumption: Emerging Concepts, Methods and Propositions, Journal of Marketing, 46, pp.92-101.

Hoffman, D.L., Novak, P.T. (1996), Marketing in Hypermedia Computer-Mediated Environments: Conceptual Foundations, Journal of Marketing, 60, pp.50-68.

Hoffman, D.L., Novak, P.T., Peralta, M.A. (1999), Building consumer trust online, Communications of the ACM, 42, pp.80-85. 
Holbrook, M.B., Hirschman, E.C. (1982), The Experiential Aspects of Consumption: Consumer Fantasies, Feelings, and Fun, Journal of Consumer Research, 9, pp.132-140.

Huang, M-H. (2000), Information load: its relationship to online exploratory and shopping behavior, International Journal of Information Management, 20, pp.337-347.

Irwin, J.R., McClelland, G.H. (2001), Misleading Heuristics and Moderated Multiple Regression Models, Journal of Marketing Research, 38, pp.100-109.

Kim, D.J., Ferrin, D.L., Raghav, R.H. (2008), A trust-based consumerdecision-making model in electronic commerce: The role of trust, perceived risk, and their antecedents, Decision Support Systems, 44, pp.544 564 .

Koiso-Kanttila, N. (2005), Time, attention, authenticity and consumer benefits of the Web, Business Horizons, 48, pp.63-70.

Lee, G-G., Lin, H-F. (2005), Customer perceptions of e-service quality in online shopping, International Journal of Retail and Distribution Management, 33, pp.161-176.

Lee, M.K.O., Turban, E. (2001), A trust model for consumer internet shopping, International Journal of Electronic Commerce, 6, pp.75-91.

Lee, M-Y., Kim, Y-K., Fairhurst, A. (2009), Shopping value in online auctions: Their antecedents and outcomes, Journal of Retailing and Consumer Services, 16, pp.75-82.

Li, Y-H., Huang, J-W. (2010), Applying Theory of Perceived Risk and Technology Acceptance Model in the Online Shopping Channel, International Journal of Human and Social Sciences, 5, pp.816-822.

Lian, J-W., Lin, T-M. (2008), Effects of consumer characteristics on their acceptance of online shopping: Comparisons among different product types, Computers in Human Behavior, 24, pp.48-65.

Neter, J., Wasserman, W., Kutner, M.H. (1990), Applied linear statistical models, Illinois: Irwin.

Nunnally, J. (1978), Psychometric Theory, McGraw-Hill, New York.

O'Brien, H.L. (2010), The influence of hedonic and utilitarian motivations on user engagement: The case of online shopping experiences, Interacting with Computers, 22, pp.344-352.

Overby, J.W., Lee, E-J. (2006), The effects of utilitarian and hedonic online shopping value on consumer preference and intentions. Journal of Business Research 59:1160-1166.

Park, Y.A., Gretzel, U. (2010), Influence of consumers' online decision-making style on comparison shopping proneness and perceived usefulness of Comparison shopping tools. Journal of Electronic Commerce Research 11:342-354.

Rao, S.S., Truong, D., Senecal, S., Le, T.T. (2007), How buyers'expected benefits, perceived risks, and ebusiness readiness influence their e-marketplace usage, Industrial Marketing Management, 36, pp.10351045.

Read, W., Robertson, N., McQuilken, L., (2011), A novel romance: The Technology Acceptance Model with emotional attachment, Australasian Marketing Journal, 19, pp.223-229.

Rohm, A., Swaminathan, V. (2004), A typology of online shoppers based on shopping motivations, Journal of Business Research, 57, pp.748-757.

Sarkar, A. (2011), Impact of utilitarian and hedonic shopping values on individual's perceived benefits and risks in online shopping, International Management Review, 7, pp.58-65.

Shang, R-A., Chen, Y-C., Shen, L. (2005), Extrinsic versus intrinsic motivations for consumers to shop online, Information \& Management, 42, pp.401-413.

Son, M., Han, K. (2011), Beyond the technology adoption: Technology readiness effects on post-adoption behavior, Journal of Business Research, 64, pp.1178-1182. 
Soopramanien, D.G.R., Robertson, A. (2007), Adoption and usage of online shopping: An empirical analysis of the characteristics of "buyers" "browsers" and "non-internet shoppers", Journal of Retailing and Consumer Services, 14, pp.73-82.

Srinivasan, S.S., Anderson, R., Ponnavolu, K. (2002), Customer loyalty in e-commerce: an exploration of its antecedents and consequences, Journal of Retailing, 78, pp.41-50.

To, P-L., Liao, C., Lin, T-H. (2007), Shopping motivations on Internet: A study based on utilitarian and hedonic value, Technovation, 27, pp.774-787.

Vijayasarathy, L.R. (2004), Predicting consumer intentions to use on-line shopping: the case for an augmented technology acceptance model, Information and Management, 41, pp.747-762.

Voss, K.E., Spangenberg, E.R., Grohmann, B. (2003), Measuring the Hedonic and Utilitarian Dimensions of Consumer Attitude, Journal of Marketing Research, 40, pp.310-320

Zhang, Y. (2000), Using the Internet for survey research: A cas e study, Journal of American Society of Information Science, 51, pp.57-68. 